\title{
Quimioprevenção do Câncer Gástrico
}

\author{
Gastric Cancer Chemoprevention \\ Quimioprevención del Cáncer Gástrico
}

Danúbia da Cunha Antunes', Iris Maria Lima e Silva², Wanise Maria de Souza Cruz ${ }^{3}$

\section{Resumo}

O câncer gástrico é a quarta neoplasia mais frequente no mundo e, no Brasil, é uma importante causa de morbimortalidade. Um dos principais fatores de risco para o câncer gástrico é a infecção pelo Helicobacter pylori. Estudos mostram que as hortaliças e frutas, por serem fontes de antioxidantes, vitaminas e minerais (os quimiopreventivos) são importantes fatores na prevenção do câncer gástrico. $\mathrm{O}$ objetivo deste trabalho consiste em analisar a associação dos quimiopreventivos na prevenção do câncer gástrico. Realizou-se uma revisão da literatura, utilizando as bases de dados eletrônicas Lilacs, Pubmed, SciELO, Periódicos Capes e fontes impressas, com as seguintes palavras-chave: quimioprevenção, antioxidantes, vegetais Allium e selênio, fatores de risco e câncer gástrico. O limite temporal foi de 15 anos de publicação (1994 a 2009) e nos idiomas português, inglês e espanhol. Os estudos têm demonstrado que

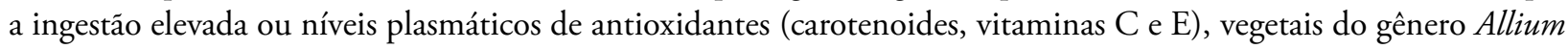
e selênio estão associados como o risco reduzido de câncer gástrico, inibição do tamanho do tumor e regressão das lesôes pré-cancerígenas. Logo, conclui-se que a quimioprevenção tem importante papel na inibição da carcinogênese gástrica, porém mais estudos são necessários para elucidar todos os mecanismos de ação e dose terapêutica.

Palavras-chave: Neoplasias Gástricas; Quimioprevenção; Helicobacter Pylori; Antioxidantes; Allium; Selênio

\footnotetext{
${ }^{1}$ Nutricionista da Equipe de Nutrição Clínica do Hospital Estadual Tavares de Macedo. Especialista em Terapia Nutricional pela Universidade do Estado do Rio de Janeiro (UERJ).

${ }^{2}$ Mestranda em Ciência dos Alimentos pela Universidade Federal do Rio de Janeiro, (UFRJ). Especialista em Nutrição Clínica pela Faculdade São Camilo do Rio de Janeiro.

${ }^{3}$ Mestre em Ciências pela UFRJ. Professora Adjunta da Universidade Federal Fluminense (UFF). Especialista em Nutrição Clínica pela UFRJ. Instituição: Universidade Federal Fluminense.

Endereço para correspondência: Danúbia da Cunha Antunes. Rua Alziro Antônio de Carvalho, lote 154. Nova Cidade - Itaboraí (RJ), Brasil. CEP: $24800-000$.

E-mails: danubiantunes@gmail.com; limairis@yahoo.com.br; wanisecruz@ig.com.br
} 


\section{INTRODUÇÃO}

O câncer tem sido uma das principais causas de morte em todo mundo e o câncer gástrico representa atualmente o quarto tumor maligno mais frequente no mundo e, no que se refere à mortalidade, é a segunda causa de óbitos por câncer no geral, com aproximadamente um milhão de óbitos por ano. Em geral, o câncer de estômago é de duas a três vezes mais frequente em países em desenvolvimento e atinge mais homens do que mulheres. No Brasil, ainda é uma importante causa de morbi-mortalidade, sendo um problema de saúde pública ${ }^{1}$.

No Brasil, estáo previstos 21.500 mil novos casos de câncer de estômago para o ano de 2010 (13.820 entre os homens e 7.680 entre as mulheres). Correspondendo a um risco estimado de 14 casos novos a cada 100 mil homens e 8 a cada 100 mil mulheres ${ }^{1}$.

A ocorrência do câncer gástrico vem sendo associada a vários fatores, como: bactérias, vírus, hábitos de vida, porém os fatores genéticos e dietéticos, como o consumo de dietas ricas em cloreto de sódio, nitrato e nitrito, contidos em alimentos defumados e industrializados, têm sido destacados.

A alta prevalência de infecção pelo Helicobacter pylori (H. pylori), sua forte tendência à cronicidade, bem como a aceitação de importante papel desse micro-organismo na patogênese de úlceras gastroduodenais, câncer gástrico e linfomas sustentam o interesse e a preocupação em relação ao assunto ${ }^{2}$.

A infecção por $H$. pylori ainda continua sendo o maior fator de risco para o desenvolvimento do câncer gástrico, aumentando cerca de seis vezes a incidência desse tipo de câncer. É uma das infecçôes mais comuns dentro da população, com uma prevalência mundial calculada entre $50 \%$ e $90 \%$ em países em desenvolvimento ${ }^{1}$. Em países, como a China, que apresentam altas taxas de incidência para $H$. pylori, ocorre um intenso paralelismo com o câncer gástrico ${ }^{3}$.

Porém, é importante mencionar que, em populaçóes com alta prevalência de infecção pelo $H$. pylori, uma pequena fraçáo infectada desenvolve o câncer gástrico. $\mathrm{O}$ risco de metaplasia intestinal no antro depende muito da presença de úlcera gástrica e de outros fatores, como exemplos idade avançada, hábito de fumar, alta frequência de consumo de álcool e hábitos alimentares, logo isso sugere que fatores adicionais alteram a relação do $H$. pylori com a carcinogênese gástrica ${ }^{4}$.

$\mathrm{O} H$. pylori também é um coadjuvante no processo de carcinogênese com o hábito de fumar, potencializando os efeitos do fumo na gastrite, tendo assim um aumento na produção de oxigênio derivado de radicais livres e um decréscimo na produçáo de muco, lesionando assim a mucosa 5 .

Outra associação interessante é a que ocorre entre o sal (cloreto de sódio) e o $H$. pylori. Há proliferação de células da mucosa no antro em pacientes com alto consumo de sal e $H$. pylori positivos ${ }^{6}$. Além disso, o cloreto de sódio em excesso resulta na formação de malonodialdeído na mucosa do estômago glandular e aumenta sua excreção pela urina. Assim, ocorre peroxidação lipídica no estômago glandular devido ao dano provocado pelo cloreto de sódio ${ }^{7}$.

Kono e Hirohata ${ }^{8}$ comprovaram, através de estudos epidemiológicos, o efeito protetor de alguns nutrientes presentes em hortaliças e frutas, como o folato, vitaminas C e E, antioxidantes, fibras e carotenoides, para o câncer gástrico.

Este trabalho de revisão da literatura teve como objetivo analisar a associação dos quimiopreventivos (antioxidantes, vegetais do gênero Allium e selênio) com a prevenção do câncer gástrico. $\mathrm{O}$ enfoque foi como a Nutrição, como ciência da saúde, pode interagir na prevenção do câncer gástrico.

\section{METODOLOGIA}

Este trabalho consiste em revisão bibliográfica realizada em fonte impressa e eletrônica. As fontes de informaçóes eletrônicas foram bases de dados Lilacs, Pubmed, SciELO e Periódicos Capes, todos consultados via online, utilizando como palavras-chave: quimioprevenção, antioxidantes, vegetais Allium, selênio, fatores de risco e câncer gástrico.

Para a seleção dos artigos, foram adotados os seguintes critérios de elegibilidade: apresentar o tema relacionado a substâncias ou nutrientes que atuam na prevenção do câncer gástrico; fatores de risco e câncer gástrico; estarem disponíveis na íntegra em bibliotecas brasileiras ou via on-line, com limite temporal de 15 anos de publicação (1994 a 2009) e nos idiomas português, inglês e espanhol.

\section{RESULTADOS E DISCUSSÃO}

Após pesquisa, foram localizados 108 artigos sobre o tema e, obedecendo-se aos critérios de inclusão previamente estabelecidos, 25 foram selecionados.

Entre os estudos que foram utilizados nesta revisão, o quadro 1 destaca sete estudos observacionais (casocontrole e coorte) e experimentais; dos quais, extraíram-se dados sobre doses de suplementação (quando utilizadas) e resultados obtidos e observados nos mesmos.

Dados observacionais epidemiológicos e dados experimentais, embora não totalmente consistentes, têm demonstrado que a ingestão elevada ou níveis plasmáticos de carotenoides, vitaminas $\mathrm{C}$ (ácido ascórbico) e $\mathrm{E}$ (tocoferol), vegetais do gênero Allium e selênio estão associados com risco reduzido de câncer gástrico (Quadro 1). 
Quadro1. Estudos observacional e experimental e a quimioprevenção do câncer gástrico

\begin{tabular}{|c|c|c|c|}
\hline Referência & $\begin{array}{l}\text { Desenho do } \\
\text { estudo }\end{array}$ & Estudo & Resultados \\
\hline $\begin{array}{l}\text { Zhang et al., } \\
1994^{13}\end{array}$ & Coorte & $\begin{array}{l}\text { Associação da } \\
\text { suplementação de } \\
\text { micronutrientes e } \\
\text { os mecanismos da } \\
\text { carcinogênese gástrica }\end{array}$ & $\begin{array}{l}\text { Suplementação de } ß \text {-caroteno, vitaminas C (ácido } \\
\text { ascórbico), E e selênio em adultos com lesões pré- } \\
\text { cancerígenas, na China. As concentrações séricas de } \\
\text { B-caroteno e ácido ascórbico foram significativamente } \\
\text { menores entre os indivíduos com metaplasia intestinal } \\
\text { do que entre os controles }(p<0,05)\end{array}$ \\
\hline $\begin{array}{l}\text { Mark et al., } \\
2000^{23}\end{array}$ & Coorte & $\begin{array}{l}\text { Associação do nível } \\
\text { sérico de selênio, após } \\
\text { suplementação, com } \\
\text { redução do câncer } \\
\text { gástrico }\end{array}$ & $\begin{array}{l}\text { O suplemento continha } 50 \text { mcg de selênio, } 15 \text { mg de } \\
\text { ß-caroteno e de } 30 \mathrm{mg} \text { de tocoferol. Foi encontrada } \\
\text { associação inversa significante entre os níveis séricos } \\
\text { de selênio com a incidência câncer gástrico na região } \\
\text { da cárdia }(p<0,05)\end{array}$ \\
\hline $\begin{array}{l}\text { Correa et al., } \\
2000^{14}\end{array}$ & Caso-controle & $\begin{array}{l}\text { Associação da } \\
\text { suplementação } \\
\text { de vitamina C, } \\
\text { B-caroteno e uso } \\
\text { de medicação anti- } \\
\text { Helicobacter pylori com } \\
\text { a quimioprevenção da } \\
\text { displasia gástrica }\end{array}$ & $\begin{array}{l}\text { Suplemento dietético de betacaroteno ( } 30 \text { mg uma } \\
\text { vez por dia) e/ou ácido ascórbico ( } 1 \mathrm{~g} \text { duas vezes ao } \\
\text { dia) e para o tratamento do Helicobacter pylori foram } \\
\text { administrados, por } 14 \text { dias, amoxicilina ( } 500 \mathrm{mg} \text { três } \\
\text { vezes por dia), metronidazol ( } 375 \mathrm{mg} \text { três vezes por } \\
\text { dia), e subsalicilato de bismuto ( } 262 \mathrm{mg} \text { três vezes } \\
\text { por dia). Todas as três intervenções resultaram em } \\
\text { aumentos estatisticamente significativos nas taxas de } \\
\text { regressão }(p<0,001 \text { ) após } 72 \text { meses de intervenção }\end{array}$ \\
\hline $\begin{array}{l}\text { Lamm } \\
\text { e Riggs, } \\
2001^{20}\end{array}$ & Experimental & $\begin{array}{l}\text { Associação do alho } \\
\text { e a inibição do } \\
\text { crescimento das } \\
\text { células do carcinoma } \\
\text { gástrico em ratos }\end{array}$ & $\begin{array}{l}\text { Significante inibição do tamanho do tumor foi } \\
\text { observada com ingestão oral de } 50 \text { e } 500 \mathrm{mg} / \text { dose } \\
\text { ( } p=0,023 \text { e } p<0,001 \text {, respectivamente), em ratos. A } \\
\text { incidência do tumor foi reduzida com a ingestão de } \\
500 \mathrm{mg} / \text { dose }(P=0,029)\end{array}$ \\
\hline $\begin{array}{l}\text { Yuan et al., } \\
2004^{16}\end{array}$ & Coorte & $\begin{array}{l}\text { Associação do nível } \\
\text { sérico de B-caroteno, } \\
\text { licopeno, vitaminas C } \\
\text { e E com redução do } \\
\text { câncer gástrico }\end{array}$ & $\begin{array}{l}\text { Níveis séricos elevados de } B \text {-caroteno e licopeno } \\
\text { foram significativamente associados com reduzido } \\
\text { risco de desenvolver câncer gástrico }(P<0,05) \text {. } \\
\text { O aumento do nível sérico de vitamina } C \text { foi } \\
\text { significativamente associado com risco reduzido de } \\
\text { câncer gástrico entre os homens que não fumavam } \\
\text { e que não consumiam } \geq 3 \text { doses de álcool/dia. Não } \\
\text { foram encontrados resultados significantes sobre a } \\
\text { vitamina } E\end{array}$ \\
\hline $\begin{array}{l}\text { Setiawan et } \\
\text { al., } 2005^{19}\end{array}$ & Caso-controle & $\begin{array}{l}\text { Associação entre o } \\
\text { consumo dos vegetais } \\
\text { Allium (alho, cebola) e } \\
\text { o câncer gástrico, nas } \\
\text { cidades de Qingdao e } \\
\text { Shanghai, China }\end{array}$ & $\begin{array}{l}\text { Associação negativa foi observada entre a ingestão } \\
\text { mensal de alho e cebola e o risco de câncer gástrico } \\
\text { em Qingdao }(p=0,02) \text { e Shanghai }(p=0,04)\end{array}$ \\
\hline $\begin{array}{l}\text { Persson et } \\
\text { al., } 2008^{12}\end{array}$ & Caso-controle & $\begin{array}{l}\text { Associação dos } \\
\text { níveis plasmáticos } \\
\text { de carotenoides } \\
\text { (ß-caroteno), retinol } \\
\text { (vitamina A) e tocoferol } \\
\text { (vitamina E), e risco de } \\
\text { câncer gástrico }\end{array}$ & $\begin{array}{l}\text { Níveis plasmáticos elevados de carotenoides são } \\
\text { inversamente associados com o risco de câncer } \\
\text { gástrico. Essa associação inversa pode ser observada } \\
\text { para } \alpha \text {-caroteno }(P<0,04) \text { e } \beta \text {-caroteno }(p<0,01) \text {. } \\
\text { Não foi observada associação estatisticamente } \\
\text { significante entre os níveis plasmáticos de retinol e } \\
\text { tocoferol e câncer gástrico }\end{array}$ \\
\hline
\end{tabular}


As vitaminas mais investigadas com propriedades quimiopreventivas sáo os carotenoides e as vitaminas $\mathrm{C}$ e $\mathrm{E}$, que funcionam como antioxidantes em sistemas biológicos. O processo carcinogênico é caracterizado por um estado oxidativo crônico, especialmente na etapa de promoção. Além disso, a fase de iniciação está associada com dano irreversível no material genético da célula, devido ao ataque de radicais livres. Desse modo, os nutrientes antioxidantes poderiam reduzir o risco de câncer inibindo os danos oxidativos no DNA ${ }^{9,10}$.

$\mathrm{O}$ retinol e seus metabólitos naturais pertencem à família dos carotenoides, bem como um grande número de análogos sintéticos. As fontes de retinol são compostas por leite integral, gema de ovo, fígado e carne. A atividade quimiopreventiva dos retinoides observada por Lotan $(1996)^{11}$ tanto em modelos experimentais quanto em alguns tipos de cânceres em humanos tem sido atribuída à ação do ácido retinoico sobre a expressáo de genes envolvidos com a diferenciação e proliferação celular.

Os carotenoides constituem uma família de mais de 600 membros já identificados na natureza, sendo que cerca de 50 apresentam atividade pró-vitamina $\mathrm{A}$ em mamíferos. O ß-caroteno é o mais abundante na natureza e é encontrado em vegetais e frutas de cor verde-escuro e amarelo-alaranjado. Algumas das maiores fontes de carotenoides são: cenouras e abóboras, tomates e produtos derivados como extrato, polpa e molhos, goiaba vermelha e espinafre ${ }^{10}$. O efeito protetor dos carotenoides, em especial do ß-caroteno, demonstrado em diferentes modelos experimentais in vitro e in vivo, tem sido atribuído a uma ação do próprio pigmento produzido a partir do seu metabolismo endógeno ${ }^{12}$.

Foi observado, por Zang et al. ${ }^{13}$, nível diminuído de ß-caroteno sérico em pacientes com lesóes précancerígenas gástrica como displasia e/ou metaplasia intestinal em população do norte da China. Correa et al. ${ }^{14}$ realizaram um estudo na Colômbia, no qual os pacientes receberam suplementaçáo de $30 \mathrm{mg} /$ dia de $\beta$-caroteno durante seis anos, resultando num aumento estatisticamente significante na taxa de regressão de lesóes gástricas.

Porém, é importante salientar que, no estudo Alpha-Tocopherol, Beta-Carotene Cancer Prevention Study $(A T B C)$, os tabagistas finlandeses que receberam $ß$-caroteno (20 mg/dia) e $ß$-caroteno mais vitamina $\mathrm{E}$ (50 $\mathrm{mg} / \mathrm{dia}$ ) não responderam positivamente à suplementaçáo; ao contrário, constatou-se nesses indivíduos um aumento de $18 \%$ na incidência de câncer de pulmão e de $8 \%$ na mortalidade total ${ }^{10}$. Logo, apesar de estudos promissores sobre a quimioprevençáo do ß-caroteno no câncer gástrico, é importante reconsiderar sobre a relação dose suplementada e prevenção do câncer em geral.

O licopeno é um carotenoide sem a atividade próvitamina $\mathrm{A}$, lipossolúvel, composto por 11 ligaçôes conjugadas e duas ligaçóes duplas não conjugadas, predominante no plasma e nos tecidos humanos, sendo encontrado em alimentos de cor vermelha, como: tomate e derivados, melancia, goiaba, mamão, pitanga ${ }^{15}$. Num estudo realizado por Yuan et al. ${ }^{16} \mathrm{em}$ Shangai, China, o licopeno foi associado com o risco diminuído de câncer gástrico por quelar eficientemente o oxigênio singlete (uma molécula no estado eletrônico excitado) e radicais livres, atribuindo assim esse efeito protetor à propriedade antioxidante.

A vitamina $C$ é uma vitamina solúvel importante e essencial para síntese de colágeno, carnitina e biogênese de neurotransmissores. Muitos benefícios para a saúde foram atribuídos a essa vitamina, como antioxidante, antiaterogênico, anticarcinogênico e imunomodulador. $\mathrm{O}$ termo vitamina $\mathrm{C}$ é uma denominação genérica para todos os compostos que apresentam atividade do ácido ascórbico. São fontes de vitamina $\mathrm{C}$ as frutas como: mamão, morango, manga, melancia, acerola, caju, goiaba e frutas cítricas e os vegetais: brócolis, couve, couve-flor e tomate ${ }^{10}$.

A vitamina $\mathrm{C}$ pode inibir o processo de carcinogênese no estômago neutralizando as espécies reativas de oxigênio que lesionam o DNA e inibir a formação de nitrosaminas in vivo a partir de nitratos e nitritos usados como conservantes; sendo, portanto, adicionada a muitos produtos industrializados para prevenir a formação desses compostos reconhecidamente carcinogênicos ${ }^{9,10}$.

Estudos epidemiológicos sugeriram uma associação da ingestão elevada de vitamina $\mathrm{C}$ e o risco reduzido de câncer de estômago, evidências bioquímicas e fisiológicas sugerem que a vitamina $\mathrm{C}$ neutraliza os radicais livres pela sua ação de antioxidante e inibe a formaçáo de compostos $\mathrm{N}$-nitrosos no estômago, que são potencialmente carcinogênicos, levando à proteçáo contra processo carcinogênico ${ }^{10}$.

Correa et al..$^{14}$ observaram redução do risco de câncer de estômago associado com altas doses de suplementação de vitamina $\mathrm{C}$, numa área de alta prevalência de câncer gástrico na Colômbia, a suplementação de vitamina $\mathrm{C}$ numa dose de $2.000 \mathrm{mg} /$ dia era associada com regressão de lesôes pré-cancerígenas.

A ingestão de alimentos salgados está envolvida no desenvolvimento de gastrites superficiais e gastrites atróficas crônicas, que podem evoluir para carcinogênese. A ingestáo de carotenoides, vitamina C e E em combinação, inibe a produção de carcinógenos $\mathrm{N}$-nitrosos, proporcionando uma proteçãa ${ }^{17}$.

Yuan et al. ${ }^{16}$ mostraram que a reduçáo do risco câncer gástrico associada com níveis aumentados de vitamina C foi estatisticamente significante, porém em homens não fumantes e que não consomem três ou mais doses de bebidas alcoólicas por dia. Como os fumantes são expostos a altos níveis de radicais livres - e o consumo 
elevado de álcool gera produção de radicais livres - os fumantes e etilistas pesados tiveram significativamente baixos níveis séricos de carotenoides e vitamina C, refletindo uma baixa ingestáo desses micronutrientes e menor concentração plasmática de antioxidantes por radicais livres. Dessa forma, os indivíduos fumantes e etilistas crônicos podem requerer uma quantidade aumentada de antioxidantes, como a vitamina $\mathrm{C}$, para prevençáo dos danos oxidativos no DNA e em outras estruturas celulares por radicais livres.

A vitamina E é uma substância lipossolúvel e existente na natureza como tocoferóis e tocotrienóis, em quatro formas diferentes, sendo o alfa-tocoferol a forma mais ativa e amplamente distribuída nos tecidos e no plasma. É um importante fator de proteção contra a peroxidação lipídica nas membranas celulares e na circulação sanguínea. Os óleos vegetais e as margarinas, além de amêndoas, amendoim e gérmen de trigo, constituem alimentos ricos em alfa-tocoferol. Essa vitamina leva a uma plausível diminuição do risco de carcinogênese, embora evidências para o efeito sejam menos convincentes que a vitamina C. Já a combinação da vitamina E, selênio e caroteno reduziram o risco de câncer de estômago ${ }^{18}$.

Observa-se que a ingestão de quantidades fisiológicas de antioxidantes, tais como as vitaminas $\mathrm{C}$ e $\mathrm{E}$ e os carotenoides, podem retardar ou prevenir o aparecimento do câncer gástrico. Assim, uma dieta rica em frutas e hortaliças, contendo quantidades dessas substâncias mais próximas das recomendaçôes nutricionais, contribui com a defesa antioxidante do organismo, inibindo danos oxidativos em macromoléculas ${ }^{18}$. $\mathrm{O}$ aporte de quantidades mais elevadas na forma de suplementos não está indicado, podendo inclusive ser deletério para o organismo, como no caso do $\beta$-caroteno em fumantes, aumentando o risco para câncer de pulmáo ${ }^{10}$.

Os vegetais do gênero Allium contêm elevados níveis de flavonoides e compostos organosulfurados, que tem ação antioxidante como também influencia o sistema imune e inibe a ação de carcinógenos no $\mathrm{DNA}^{19}$.

O gênero Allium inclui aproximadamente 500 espécies, os representantes desse gênero são o alho, a cebola, o alho-porro e cebolinhas verdes; são agentes flavorizantes muito presentes na culinária em geral. Os compostos protetores nos vegetais Allium são sulfetos alil, incluindo dialil sulfeto e dialil dissulfeto. Vários outros sulfetos estão presentes, mas o grupo alil é necessário para a atividade protetora, especialmente como um indutor de glutationa transferase ${ }^{19}$.

O alho vem sendo utilizado no tratamento do câncer desde 1550 quando os egípcios antigos administravam o extrato oralmente. O alho é cultivado amplamente e mundialmente consumido, seu efeito benéfico é conhecido há milhares de anos, atua na longevidade, vermífuga, é antisséptico, antipirético e analgésico ${ }^{20}$.
Vários mecanismos foram propostos para explicar os efeitos protetores do alho e da cebola, incluindo a inibição da mutagênese, modulação da atividade de enzimas, atividade antioxidante, estimulaçáo da atividade da glutationa peroxidase e inibição da proliferação e do crescimento do tumor ${ }^{20}$.

$\mathrm{O}$ alho tem a capacidade de estimular a proliferação de macrófagos, Natural Killer, linfócitos, aumentam a produção de Interleucina-2 (Il-2), Fator de Necrose Tumoral- $\alpha$ (TNF- $\alpha$ ) e Interferon- $\gamma$ (INF- $\gamma$ ). Estudos adicionais são exigidos para identificar os componentes ativos do alho responsáveis pela atividade anticarcinogênica e a estimulaçáo do sistema imune. Há evidências de que a molécula de enxofre e F4 são os responsáveis pela estimulação. A fração F4 é uma fração proteica que estimula o sistema imune, aumentando a atividade citotóxica e fagocitária dos macrófagos, estimula a proliferaçáo e citotoxicidade dos linfócitos e estimula IL-2. Embora a fração F4 seja um estimulador do sistema imune, não é o único ingrediente imunologicamente ativo no alho. Sundaram e Milner ${ }^{21}$ acharam que o dialil sulfeto parece ser táo ativo quanto o 5-FU (5-fluorouracil - antineoplásico), inibindo o crescimento do tumor. Além disso, o alho inibe a ativaçáo de procarcinógenos através da enzima citocromo P450, da atividade de antioxidante ou pela ligaçẫo com o enxofre.

Estudos em animais, realizados por Nakagama $e_{\text {al }} .^{22}$, mostraram que os vegetais do gênero Allium têm um potencial anticarcinogênico, com um efeito antibacteriano contra o $H$. pylori. A inibição do crescimento bacteriano na cavidade gástrica resulta na redução da conversão de nitrato para nitrito, diminuindo a formação endógena dos carcinógenos $\mathrm{N}$-nitrosos e redução da infecção por $H$. pylori. $\mathrm{O}$ efeito antibacteriano é atribuído à concentração de tiosulfeto, que é responsável pelo sabor e odor do alho.

Foi achado por Setiawan et al. ${ }^{19}$ que o consumo de cebola e alho é associado inversamente com o risco de câncer de estômago distal em Shanghai e Qingdao (China). Nakagama et al. ${ }^{22}$ demonstraram que os vegetais do gênero Allium podem inibir a proliferação, bloquear o ciclo celular e/ou apoptose nas células cancerígenas, além disso, os bioativos do enxofre, presentes na cebola e no alho deprimem a formação de nitrosaminas in vitro.

Evidências mostram que os vegetais Allium, principalmente o alho e alil, têm efeitos preventivos no câncer gástrico, inibindo a mutagênese, com ação antioxidante combatendo os radicais livres e estimulando a atividade da enzima glutationa peroxidase ${ }^{19}$. Contudo, carecem dados mais consistentes sobre a estabilidade dos compostos organosulfurados durante o cozimento ou sobre seu metabolismo, farmacocinética e a toxicidade das combinaçóes ativas em humanos. Devido a todos esses aspectos, deve-se ter atenção adicional para uso dos vegetais Allium e para sua recomendação na prevenção do câncer gástrico. 
O selênio é um mineral com propriedades anticancerígenas. Muitos estudos nos últimos anos mostraram que o selênio é um nutriente protetor potente para algumas formas de câncer. Dois mecanismos de açáo foram propostos para explicar o efeito protetor deste mineral: 1) o primeiro envolve a participação do selênio na molécula de selenoenzimas com função antioxidante e pode proteger contra a iniciaçáo do câncer; 2) o segundo envolve a atuaçáo dos metabólitos do selênio, interferindo no processo de carcinogênese e na fase de progressão do câncer. $\mathrm{O}$ selênio está envolvido no reparo e prevenção de danos oxidativos, sinalizaçáo intracelular, ativação de hormônio da tireoide, regulação da resposta imune e apoptose $\mathrm{p} 53$-independente ${ }^{9,23}$.

Num estudo realizado por Seo et al..$^{24}$, foi visto que o selênio participa da composição das enzimas glutationa peroxidase e tioredoxina redutase, que têm propriedades antioxidantes e mantêm o equilíbrio redox nas células. Foi utilizado como fonte de selênio a selenometionina (SeMet), principal componente do selênio dietético que sofre uma reação de transulfuraçáo para selenocisteína, que compóe as enzimas. A atividade específica de ambas as enzimas antioxidantes são altamente sensíveis à concentração do selênio no ambiente celular. Tioredoxina redutase também é essencial para conversão de ribonucleotídeos para desoxirribonucleotídeos, necessários para a síntese de DNA e por regular vários fatores de transcrição.

Seo et al..$^{24}$ mostraram que o selênio atua na redução da cisteína na proteína P53 supressor de tumor, levando a um aumento na eficiência do reparo de DNA. Eles demonstraram que a SeMet pode ativar P53 e essa ativação é dependente de Ref-1, proteína que atua no reparo do DNA e tem atividade redox. A P53 não é ativada quando tem um Ref-1 alterado, o acréscimo de SeMet aumenta a eficiência no reparo do DNA, por ativar a P53.

Estudos observacionais demonstraram que níveis elevados de selênio reduzem o risco de câncer gastrointestinal em populaçóes com déficit de selênio ${ }^{13,23}$, porém é importante mencionar que estes estudos não forneceram apenas a suplementação de selênio, mas também de outros nutrientes antioxidantes. Logo, não é possível caracterizar que a reduçáo do risco do desenvolvimento do câncer seja atribuída somente ao selênio.

O selênio reduz o risco de câncer gástrico, por estar presente na composição das enzimas antioxidantes glutationa peroxidase e a tioredoxina redutase que inibem o processo de iniciaçáo do câncer e melhoram a resposta imune. A suplementação se faz necessário quando o paciente tem déficit desse mineral, não sendo indicada a suplementaçáo com a intenção de prevenção do câncer gástrico ${ }^{25}$.

\section{CONCLUSÃO}

A quimioprevenção tem um importante papel na inibição da carcinogênese gástrica por aumentar a apoptose epitelial, reverter lesóes pré-cancerígenas e estimular o sistema imune; os antioxidantes neutralizam espécies reativas de oxigênio, que lesionam o DNA, diminuem a progressão de lesóes gástricas, através da inibição da formação de composto $\mathrm{N}$-nitrosos, entre outros papéis ainda náo explorados.

Porém, o uso de suplementos de forma aleatória com o intuito de promover a quimioprevenção náo é indicado, devendo a ingestáo ser em quantidades fisiológicas, pois o suprimento de quantidades mais elevadas, na forma de suplementos, pode ser deletério para o organismo, conforme constatado no estudo de suplementação de ß-caroteno em fumantes. Além disso, mais estudos são necessários para comprovar os benefícios desses nutrientes, elucidar os mecanismos de ação envolvidos e a dose terapêutica.

\section{Declaraçáo de Conflito de Interesses: Nada a declarar. REFERÊNCIAS}

1. Instituto Nacional de Câncer (Brasil). Estimativa 2010: incidência de câncer no Brasil. Rio de Janeiro: INCA; 2009.

2. Caetano A, Felix VN, Coimbra FTV, Ganc AJ. Helicobacter pylori e doença péptica. Estudo comparativo de métodos diagnósticos. Arq Gastroenterol 2008; 45(3): 255-7.

3. Kelley JR, Duggan JM. Gastric cancer epidemiology and risk factors. J Clin Epidemiol 2003; 56 (1):1-9.

4. Jedrychowski W. Contribution of epidemiology in Poland for better understanding of the natural history of diseases in gastrointestinal tract. J Physiol Pharmacol 2003; 54 Suppl 3: 245-61.

5. Shimoyama T, Everett $S$, Fukuda S, Axon A, Dixon M, Crabtree J. Influence of smoking and alcohol on gastric chemokine mRNA expression in patients with Helicobacter pylori infection. J Clin Pathol 2001; 54(4): 332-4.

6. Van den Brandt PA, Botterweck AA, Goldbohm RA. Salt intake, cured meat consumption, refrigerator use and stomach cancer incidence: a prospective cohort study (Netherlands). Cancer Causes Control 2003; 14(5): 427-38.

7. Shils ME, Shike M. Suporte Nutricional do Paciente com Câncer. In: Shils ME, Olson JA, Shike M, et al. Tratado de Nutrição Moderna na Saúde e na Doença. 9a ed. São Paulo: Manole; 2003. p.1385-413.

8. Kono S, Hirohata T. Nutrition and stomach cancer. Cancer Causes Control 1996; 7(1):41-55.

9. Liu C, Russell RM. Nutrition and gastric cancer risk: an update. Nutr Rev 2008; 66 (5): 237-49.

10. Silva CRM, Naves MMV. Suplementação de vitaminas na prevenção de câncer. Rev Nutr 2001;14 (2):135-43. 
11. Lotan R. Retinoids in cancer chemoprevention. FASEB J 1996; 10(9):1031-9.

12. Persson C, Sasazuki S, Inoue M, Kurahashi N, Iwasaki M, Miura T, et al. Plasma levels of carotenoids, retinol and tocopherol and the risk of gastric cancer in Japan: a nested case-control study. Carcinogenesis 2008; 29 (5):1042-8.

13. Zhang L, Blot WJ, You WC, Chang YS, Liu XQ, Kneller $\mathrm{RW}$, et al. Serum micronutrients in relation to precancerous gastric lesions. Int J Cancer 1994; 56 (5): 650-4.

14. Correa P, Fontham ET, Bravo JC, Bravo LE, Ruiz B, Zarama G, et al. Chemoprevention of gastric dysplasia: randomized trial of antioxidant supplements and antihelicobacter pylori therapy. J Natl Cancer Inst 2000; 92 (23):1881-8.

15. Shami NJIE, Moreira EAM. Licopeno como agente antioxidante. Rev Nutr 2004; 17 (2): 227-36.

16. Yuan JM, Ross RK, Gao YT, Qu YH, Chu XD, Yu MC. Prediagnostic levels of serum micronutrients in relation to risk of gastric cancer in Shanghai, China. Cancer Epidemiol Biomarkers Prev 2004;13 (11):1772-80.

17. Riboli E, Norat T. Epidemiologic evidence of the protective effect of fruit and vegetables on cancer risk. Am J Clin Nutr 2003; 78 Suppl 3: 559-69.

18. Larsson SC, Bergkvist L, Wolk A. Fruit and vegetable consumption and incidence of gastric cancer: a prospective study. Cancer Epidemiol Biomarkers Prev 2006; 15(10):1998-2001.

19. Setiawan VW, Yu GP, Lu QY, Lu ML, Yu SZ, Mu L, et al. Allium vegetables and stomach cancer risk in China. Asian Pac J Cancer Prev 2005; 6(3):387-95.

20. Lamm DL, Riggs DR. Enhanced immunocompetence by garlic: role in bladder cancer and other malignancies. J Nutr 2001;131 Suppl 3: 1067-70.

21. Sundaram SG, Milner JA. Diallyl disulfide suppresses the growth of human colon tumor cell xenografts in athymic nude mice. J Nutr 1996; 126(5):1355-61.

22. Nakagawa H, Tsuta K, Kiuchi K, Senzaki H, Tanaka $\mathrm{K}$, Hioki K, et al. Growth inhibitory effects of diallyl disulfide on human breast cancer cell lines. Carcinogenesis 2001; 22(6): 891-7.

23. Mark SD, Qiao YL, Dawsey SM, Wu YP, Katki H, Gunter EW, et al. Prospective study of serum selenium levels and incident esophageal and gastric cancers. J Natl Cancer Inst 2000; 92(21):1753-63.

24. Seo YR, Kelley MR, Smith ML. Selenomethionine regulation of $\mathrm{p} 53$ by a ref1-dependent redox mechanism. Proc Natl Acad Sci USA 2002; 99 (22):14548-53.

25. Camargo MC, Burk RF, Bravo LE, Piazuelo MB, Hill KE, Fontham ET, et al. Plasma selenium measurements in subjects from areas with contrasting gastric cancer risks in Colombia. Arch Med Res 2008; 39 (4): 443-51. 


\section{Abstract}

Gastric cancer is the fourth most common neoplasia in the world and, in Brazil, it is a major cause of morbidity and mortality. One of the main risk factors for gastric cancer is infection by Helicobacter pylori. Studies have shown that vegetables and fruits are important factors in gastric cancer prevention, since they are sources of antioxidants, vitamins and minerals (chemopreventives). This study aims to analyze the association of chemopreventives for gastric cancer prevention. A literature review was carried out by using electronic databases like Lilacs, Pubmed, SciELO, Periodicos Capes and printed sources, with the following keywords: chemoprevention, antioxidants, Allium vegetables, selenium, risk factors and gastric cancer. The time limit was 15 years of publication (1994 to 2009) in Portuguese, English and Spanish. Studies have shown that high intake or antioxidants plasma levels (carotenoids, vitamins $\mathrm{C}$ and $\mathrm{E}$ ), vegetables of the genera Allium and selenium are associated with reduced risk of gastric cancer, tumor size inhibition and regression of precancerous lesions. In conclusion, chemoprevention plays an important role in gastric carcinogenesis inhibition; however, more studies are required to elucidate all mechanisms of both action and therapeutic dose.

Key words: Neoplasias Gástricas; Quimioprevención; Helicobacter pylori; Antioxidantes; Allium; Selenio

\section{Resumen}

El cáncer gástrico es la cuarta neoplasia más común en el mundo y, en Brasil, es una causa importante de morbimortalidad. Uno de los principales factores de riesgo para el cáncer gástrico es la infección por Helicobacter pylori. Estudios muestran que las verduras y frutas, que son fuentes de antioxidantes, vitaminas y minerales (los quimiopreventivos) son factores importantes en la prevención del cáncer gástrico. El objetivo de este estudio es analizar la asociación de los quimiopreventivos en la prevención del cáncer gástrico. Se realizó una revisión de la literatura, utilizando las bases de datos electrónicas Lilacs, PubMed, SciELO, Periodicos Capes y fuentes impresas, con las siguientes palabras clave: quimioprevención, antioxidantes, vegetales Allium y selenio, factores de riesgo y cáncer gástrico. El límite temporal fue del 15 años de publicación (1994 hasta 2009) y en los idiomas portugués, inglés y español. Los estudios han demostrado que la ingestión elevada o los niveles plasmáticos de antioxidantes (carotenoides, vitamina C y E), vegetales del género Allium y selenio están vinculados a la reducción del riesgo de cáncer gástrico, la inhibición del tamaño tumoral y la regresión de las lesiones precancerosas. Por lo tanto, se concluye que la quimioprevención tiene un importante papel en la inhibición de la carcinogénesis gástrica, pero se necesitan más estudios para aclarar todos los mecanismos de acción y la dosis terapéutica.

Palabras clave: Stomach Neoplasms; Chemoprevention; Helicobacter pylori; Antioxidants; Allium; Selenium 